\title{
Prognostic Importance of Hyponatremia in Acute STEMI
}

\author{
Hare Krishna Sharma', Chinky Sharma², Ajay Kumar ${ }^{3}$ \\ ${ }^{1}$ Assistant Professor, Department of Medicine, TMMC\&RC, Moradabad, ${ }^{2}$ Senior Resident, Department of Medicine, TMMC\&RC, Moradabad, ${ }^{3}$ Professor, \\ Department of Medicine, TMMC\&RC, Moradabad.
}

\section{Abstract}

Background: Hyponatremia develops in early phases of acute myocardial infarction, recently, several studies showing its importance as important early prognostic tool. Many studies shown that significant increase in plasma AVP level was in patients who had associated with complication as heart failure and fatal outcome after acute MI, and clinical improvement was noted following the rise in serum plasma level of sodium. hence Early developed hyponatremia is a unique indicator of neuro hormonal activity in the early phases of recent MI, so it can help predict the complication as long-term development of HF and death. OBJECTIVE: To observe the prognostic importance of hyponatremia in settings of acute STEMI event and helpfulness in prediction of short term and long term survival. Subjects and Methods: Randomized double blinded study, in 100 of patients with acute S TEMI presented to outpatient department and indoor emergency patients. Results: Patients who developed hyponatremia at admission had higher mortality rate than the patients who developed hyponatremia at 72 hrs and normonatremic patients. Mortality in patients correlates with the severity of hyponatremia 5(100\%) patient died with sodium levels <130mmol/1 whereas $5(16 \%)$ death occurred in the patient having sodium level between 131-134. (Odds ratio 6.0, p value 0.02). Conclusion: We concluded that hyponatremia developed in early as well as late phases of acute STEMI serve as is an 'independent determinant of both short term (in hospital mortality, development of arrhythmias and heart failure) as well as long term survival (cardiac death, post discharge heart failure). Plasma sodium levels may help identify patient at risk.

Keywords: Hyponatremia, STEMI, Prognosis, Heart Failure.

Corresponding Author: Dr. Chinky Sharma, Senior Resident, Department of Medicine, TMMC\&RC, Moradabad.

Received: December 2019

Accepted: December 2019

\section{Introduction}

Cardiovascular disease accounts for approx. 14 million deaths annually and to the common cause of death globally. Since past 3 decades there is considerable decline in incidence and prevalence of coronary artery disease in the industrialized western world, whereas increasing in the developing world. Coronary artery disease; deaths rates currently are 3 times more than the stroke rate.

In Community studies, it has been shown consistently that patients with suspected acute cardiac event like myocardial infarction or acute coronary syndrome, total case fatality ratio in the first month is more than $60 \%$, and half of that occur within early hours in less than $2 \mathrm{hrs}^{[1]}$

Hyponatremia ,a commonly occurring electrolyte deficiency found in inpatient department, ${ }^{[2]}$ more especially in cardiac care units, in surgical postoperative wards and in patients with cardiac failure. ${ }^{[3-5]}$ It has been shown as important prognostic indicator of cardiovascular morality in patients of cardiac failure. ${ }^{[6,7]}$ In congestive cardiac failure (CCF), decreased sodium levels are linked with over activity of renin-angiotensin-aldosterone system. Catecholamine's arginine vasopressin (AVP) and baroreceptor-mediated hormones,

Hyponatremia develops in early phases of acute myocardial infarction, recently, several studies shows the importance of hyponatremia as important early prognostic tool. Many studies shown that significant increase in plasma AVP level was in patients who had associated with complication as heart failure and fatal outcome after acute MI, and clinical improvement was noted following the rise in serum plasma level of sodium. Plasma. ${ }^{[8,9]}$ So we therefore hypothesized, presence of hyponatremia in the initial settings of acute MI suggest, at least in parts, cause increased neuro hormonal activity and affects left ventricular remodeling in acute phase of STEMI. Thus Patients presents with decreased plasma sodium levels may be attributable at much long term risk in development cardiac failure arrhythmias and mortality.

Therefore, the purpose of the this study was to test the hypothesis that hyponatremia developed early, an easy marker of neuro hormonal activation during the acute cardiac event, may predict the short term and long term complication like heart failure and death. To this end, we studied the importance of hyponatremia as prognostic marker along with impact on left ventricular ejection fraction (LVEF) in a cohort of patients who survived their index MI.

\section{Subjects and Methods}

In this proposed randomized double blinded study, 100 
patients with STEMI presented outdoor and indoor emergency unit in Teerthanker Mahaveer Hospital, Moradabad. Study was explained in details to every individual and assurance of confidently was done with written consent. 3 months follow up was done.

\section{Inclusion Criteria:}

All patients of chest pain diagnosed as STEMI presented to Teerthanker Mahaveer Hospital, Moradabad with:

- Individuals with Age > 16 years

- Chest discomfort or pain occurring for more than 20 minutes

Definitive ECG change consisting of

i) ST elevation $>1 \mathrm{~mm}$ in more than two contagious limb leads.

ii) ST elevation $>2 \mathrm{~mm}$ in more than two contagious precordial leads.

\section{Exclusion Criteria:}

- Individuals of age $<16$ years

- All patients diagnosed as acute cardiac event other than STEMI

\section{Protocol:}

1) Thorough detailed present History with details of family, personal and past history of diabetes and proper cardiac as well as physical examination will be done.

2) Physical examination emphasis on body mass index that includes height and weight in $\mathrm{kg}$ and meter respectively

3) Blood pressure to be measured after proper rest of 10 minutes in right hand supine position An Electro cardiogram to be obtained at presentation and serial hourly recording to be done

4) After an overnight fasting, blood was taken through indwelling cannula placed in antecubital vein for general routine investigation and serum sodium levels were obtained at presentation at $0 \mathrm{hrs}$ then, $24 \mathrm{hr}, 2 \mathrm{nd}$ day(48 hrs) and $3 \mathrm{rd}$ day (72 hours), I, II and III month. All blood samples were tested in lab of Biochemistry.

5) Regular follow up was done till 3 months for observing the prognostic importance of hyponatremia in the setup of STEMI and looking for development of cardiac failure with symptoms of newer onset dyspnea or pulmonary edema along with definite sign, gallop rhythm, bilateral post tussiv rales in at least1/3 of lower lung fields, jugular venous pressure elevation, or congestion of pulmonary vasculature on chest x-ray with alveolar and interstitial edema) and mortality during stay in hospital (short term) and after 3 months of discharge duration long term

\section{Results}

Table 1: Showing Hyponatremia on Admission, 72 Hrs, and 2 Months and Outcome

\begin{tabular}{|c|c|c|c|c|}
\hline & \multirow{2}{*}{$\begin{array}{l}\text { Normal } \\
\text { sodium } \\
\text { levels } \\
(n=65)\end{array}$} & \multicolumn{3}{|c|}{ Hyponatremia } \\
\hline & & $\begin{array}{l}\text { At the } \\
\text { time of } \\
\text { admission } \\
(n=11)\end{array}$ & $\begin{array}{l}\text { At } 72 \text { hrs } \\
(n=15)\end{array}$ & $\begin{array}{l}\text { At } 2 \\
\text { months } \\
(n=9)\end{array}$ \\
\hline $\mathrm{CHF}$ & $\begin{array}{l}8 \\
(12.30 \%)\end{array}$ & $5(45.00 \%)$ & $6(40.00 \%)$ & $4(44.5 \%)$ \\
\hline $\begin{array}{l}\text { Outcome } \\
\text { (Deaths) }\end{array}$ & $3(4.60 \%)$ & $4(36.36 \%)$ & $3(20.00 \%)$ & $3(33.00 \%)$ \\
\hline Arrhythmia & $\begin{array}{l}11 \\
(16.00 \%)\end{array}$ & $5(45.27 \%)$ & $6(40.00 \%)$ & $5(44.00 \%)$ \\
\hline
\end{tabular}

Patients with hyponatremia developed poorer outcome in both short and long term, A total 23(23\%) patients developed heart failure and 13 (13\%) patients died.

Congestive heart failure and the hospital death occurred in $5(45 \%)$ and $4(36 \%)$ of the patient respectively who presented with hyponatremia at admission and $72 \mathrm{hrs}$. (40\%, 20\%), the incidence of $\mathrm{CHF}$ and death was quite less in patient with normal sodium level.

$4(44 \%)$ of hyponatremias had complaints of worsening CHF at 2 nd month during follow up and 3 patients (33\%) who were hyponatremia at 2 nd month had suffered cardiac death. Arrhythmias developed in $27(27 \%)$ of patients, 11(16\%) of normal patients while $42 \%$ of hyponatremia patients developed arrhythmias within 72 hrs. and 5(44\%) patients presented with arrhythmia after discharge during follow up at 2nd month.

Table 2: Showing Hyponatremia on Admission, At 72 Hours and At 2 Months and Outcome In Terms Of Mortality

\begin{tabular}{|c|c|c|c|c|}
\hline & \multirow{2}{*}{$\begin{array}{l}\text { Normal } \\
\text { sodium } \\
\text { levels }\end{array}$} & \multicolumn{3}{|c|}{ Hyponatremia } \\
\hline & & $\begin{array}{l}\text { At the time } \\
\text { of admission }\end{array}$ & At 72 hrs & $\begin{array}{l}\text { At } 2 \\
\text { months }\end{array}$ \\
\hline $\begin{array}{l}\text { No. of } \\
\text { patients }\end{array}$ & 65 & 11 & 15 & 9 \\
\hline Mortality & $3(4.61 \%)$ & $4(36 \%)$ & $3(20 \%)$ & $3(33 \%)$ \\
\hline
\end{tabular}

Patients who developed hyponatremia at admission had higher mortality rate $(36 \%)$ than the patients who developed hyponatremia at $72 \mathrm{hrs}$. (20\%) and normonatremic patients, this difference is may be due the neuro hormonal activation in early phase of STEMI. While increase in mortality at 2 nd month can be described due to presence of several complications.

Table 3: Showing Severity of Hyponatremia and Outcome In Terms Of Mortality

\begin{tabular}{|l|l|l|l|}
\hline $\begin{array}{l}\text { Range of sodium } \\
\text { levels in } \\
\text { hyponatremia } \\
\text { patients }\end{array}$ & $\begin{array}{l}\text { No. of } \\
\text { patients }\end{array}$ & Mortality & $\begin{array}{l}\text { Odds } \\
\text { Ratio } \\
\text { p value }\end{array}$ \\
\hline$<130$ & 5 & $5(100 \%)$ & 6.0 \\
\hline $131-134$ & 30 & $5(16.66 \%)$ & 0.02 \\
\hline
\end{tabular}

Mortality in patients correlates with the severity of hyponatremia $5(100 \%)$ patient died with sodium levels $<130 \mathrm{mmol} / 1$ whereas $5(16 \%)$ death occurred in the patient having sodium level between131-134. (Odds ratio 6.0, value 0.02 )

Multivariate analyzing logistic regression analysis was performed which showed that hyponatremia was the significant predictor of both short term (development of cardiac failure, in hospital mortality and new onset arrhythmia) and long term outcome (post discharge heart failure, cardiac death)

\section{Discussion}

This study shows that the hyponatremia is frequently present in patients in early stages of STEMI. Hyponatremia if diagnosed early could be an important independent tool in detection of deterioration of $\mathrm{CHF}$ in hospitalized patients to overcome short term mortality. Moreover, we also found that early detection of hyponatremia could also useful predictor of heart failure and development of arrhythmias, and in the 
long term for prediction of cardiac mortality. This study inspired us for need for careful monitoring in s heart failure, arrhythmias in patients, if hyponatremia discovered early In Patients, diagnosed as case acute STEMI elevation myocardial infarction who were hyponatremia during admission In our study, Total of $35 \%$ patient have hyponatremia (serum sodium level, < 136mmol/l), 11 patients $(11 \%)$ being detected as hyponatremia on admission., then 15 patients (15\%) develops hyponatremia in first 72 hours of hospitalization, and fraction of patient who developed hyponatremia in the end of 2 months were 9 percent after discharge during follow ups.

Goldberg et al, ${ }^{[10]}$ conducted similar study, $32.2 \%$ cases with STEMI developed hyponatremia during admission, 13 patients $(12.5 \%)$ in first $24 \mathrm{hrs}$. and 208 (19.9\%) patients developed low serum sodium level in the first $72 \mathrm{hrs}$. in hospitals. Total of 978 patients with STEMI with follow up in median duration of 31 months (range, 9-61 months) after hospital stay. 108 patients $(11.0 \%)$ had hyponatremia in hospital. Tang Q, et al, [11] studied the relation of hyponatremia and hospital stay outcomes Chinese population with STEMI. Among 1, 620 patients, hyponatremia were reported in total of $212(13.1 \%)$ (Sodium $<136 \mathrm{mmol} / \mathrm{l}$ ).

Similarly Tada $\mathrm{Y}$, et al, ${ }^{[12]}$ found that $3.6 \%$ of patients develops hyponatremia on admission, 20.7\%(29 patients) $9.2 \%$ (13 patients ) during time of discharge.

218 patients were studied in a study by Havana $S$, et al, [13] (68 females, with mean age $64 \pm 13$ years) without prior history of cardiac event were admitted and 33\% (72) cases reported as hyponatremia; $23.4 \%$ (51) $9.6 \%$ (21) during admission and later during discharge.

Our study shows $23 \%$ (23 cases) detected with heart failure, $41 \%$ (15) were hyponatremia and $12 \%$ normonatremic patients, during admission $45 \%$ patients (odds ratio 5.93; $\mathrm{p}=0.001 \%$ ) were hyponatremia, thus in accordance to Goldberg A, et al. ${ }^{[10]}$ Low serum sodium levels during repeated admission for HF was greater in patients who were hyponatremia during the first hospital admission $(47.7 \%$ vs $23.1 \% ; \mathrm{p}=.02)$. In a study done by Aziz $\mathrm{M}$ et al, ${ }^{[14]}$ heart failure developed in 22.5 of the patients (33\% hyponatremic $\mathrm{v} / \mathrm{s} 12 \%$ in normal).

\section{Conclusion}

- In our study many patients who suffered myocardial infarction had hyponatremia at admission some had hyponatremia later in hospital or after discharge.

- Older age, diabetes, smoking, lower left ventricular ejection fraction was significantly associated with patients who developed hyponatremia as compared to normal patients.

- Development of heart failure during, and post discharge CHF were more frequent in patients who developed hyponatremia than normal patients.
- There is significant linear relationship between severity of hyponatremia with mortality and heart failure.

- Occurrence of arrhythmias were more common in hyponatremia group than normal group.

- Multivariate analysis performed, it identified that hyponatremia at initial or later stages of hospitalization can be an important independent indicator of short term and long term outcome.

We concluded that early or late development of hyponatremia in settings of acute ST elevation myocardial infarction is an important determinant of both short term (in hospital mortality, development of cardiac arrhythmias and heart failure) as well as long term outcome (cardiac death, post discharge heart failure). Thus serum sodium levels may help as unique tool to identify patient at risk.

\section{References}

1. Tunstall-Pedoe H, Kuulasmaa K, Mahonen M, Tolonen H, Ruokokoski E, Amouyel P. Contribution of trends in survival and coronary-event rates to changes in coronary heart disease mortality: 10-year results from 37 WHO MONICA project populations. Monitoring trends and determinants in cardiovascular disease. Lancet 1999; 353: 1547-57.

2. Anderson RJ, Chung HM, Kluge R, Schrier, RW. Hyponatremia: a prospective analysis of its epidemiology and the pathogentic role of vasopressin. Ann Intern MKed. 1985; 102 (2): 164-8

3. Chung HM, Kluge, R, Schrier, RW, Anderson RJ. Postoperative hyponatremia A prespective study. Arch interm Med 1986: 146: 333-6

4. Kluge R. Body fluid volume regulation in health and disease unifying hypothesis: Ann Interm Med 1990: 113: 155-9

5. Schreir RW, Abramham, WT. Hormones and hemodynamics in heart failure. N Engl J Med 1999; 341: 557-85

6. Lee WH, Packer M. Prognostic importance of serum sodium concentration and its modification by converting enzyme inhibition in patient with severs chronic. Hyponatremia. Circulation 1986: 73: 25767.

7. Sigurdsson A, Held P, Swedberg K. Short and long term neurohormonal activation following acute myocardial infarction. Am Heart J 1993; 126 : 1068-76

8. Flear CT, Hilton P. Hyponatremia and severity and outcome of myocardial infarction. Brit Med J 1979; 1: 1242-6.

9. Oren RM. Hyponatremia in congestive heart failure. Am J Cardiol 2005; 95: 2B-7B.

10. Goldberg A, Hammerman H, Petcherski S, Nassar M, Zdorovyak A, Yalonetsky S, et al. Hyponatremia and long term mortality in survivors of acute ST elevation myocardial infarction; Arch Intern Med 2006; 166: 781-6.

11. Tang Q, Hua Q. Relationship between hyponatremia and in-hospital outcomes in Chinese patients with ST-elevation myocardial infarction. Intern Med 2011; 50(9): 969-74.

12. Tada Y, Nakamura T, Funayama H, Sugawara Y, Ako J, Ishikawa SE, et al. Early development of hyponatremia implicates short- and longterm outcomes in ST-elevation acutemyocardial infarction. Circ J 2011; 75: 1927-33.

13. Štěpán Havránek, Jan Bělohlávek, Roman Škulec, Tomáš Kovárník, Vladimír Dytrych. Long-term prognostic impact of hyponatremia in the ST-elevation myocardial infarctionFebruary 2011; 71(1): 38-44.

14. Aziz M, Ullah M, Azam MG, Hossain M. In Hospital Outcome of Acute ST Elevation Myocardial Infarction with Hyponatraemia. Department of Cardiology, NICVD, Dhaka. Cardiovasc J 2009; 2(1) : $37-42$.

Copyright: () the author(s), 2019. It is an open-access article distributed under the terms of the Creative Commons Attribution License (CC BY 4.0), which permits authors to retain ownership of the copyright for their content, and allow anyone to download, reuse, reprint, modify, distribute and/or copy the content as long as the original authors and source are cited.

How to cite this article: Sharma HK, Sharma C, Kumar A. Prognostic Importance of Hyponatremia in Acute STEMI. Acad. J Med. 2019;2(2):148-50. 